Vol. 11 (2002): 51-58.

\title{
Production of a cellulosic substrate susceptible to enzymatic hydrolysis from prehydrolyzed barley husks
}

\author{
Ana Belén Moldes, José Manuel Cruz, José Manuel Domínguez and Juan Carlos Parajó \\ Departamento de Enxeñería Química, Universidade de Vigo (Campus Ourense), Edificio Politécnico, As Lagoas, \\ ES - 32004 Ourense, Spain, e-mail: jcparajo@uvigo.es
}

\begin{abstract}
An effective process for the chemical-biotechnological utilization of barley husks is reported. A first treatment with sulfuric acid (prehydrolysis) allowed the solubilization of hemicelluloses to give xylose-containing liquors (suitable to make fermentation media for xylitol production) and a solid phase containing cellulose and lignin. The solid residues from prehydrolysis were treated with $\mathrm{NaOH}$ in order to increase their cellulase digestibility. In the alkaline treatments, the effects of temperature (in the range, $\left.50-130^{\circ} \mathrm{C}\right)$, reaction time $(10-60 \mathrm{~min})$ and $\mathrm{NaOH}$ concentration $(3-10$ weight percent of solution) on the composition of solid residues were assessed by means of an experimental plan with factorial structure. The cellulose content increased with temperature and $\mathrm{NaOH}$ concentration, whereas the duration of treatments was not influential within the range tested. The treated samples showed high susceptibility toward the enzymatic hydrolysis with cellulases, leading to almost quantitative glucose yields under selected operational conditions.
\end{abstract}

Key words: barley husks, hydrolysis, alkali treatment, cellulose, xylitol

\section{Introduction}

Barley husk is an agricultural byproduct whose direct utilization as a carbohydrate source (for example, as feed supplement or for manufacture of glucose or ethanol) is hindered by its low digestibility. On the other hand, the combustion of barley husk is difficult owing to its comparatively high ash content. In this scope, the sequential processing of barley husk with sulfuric acid and $\mathrm{NaOH}$ allows the separation of two fractions (hemicellulose as soluble sugars in the first processing step and a cellulosic solid phase in the second processing step) which can be utilized by fermentation and enzymatic hydrolysis, respectively.

The processing of lignocellulosic substrates in acidic media (prehydrolysis) is carried out to convert the hemicellulose polysaccharides (xylan, mannan and galactan) into the correspondent monosaccharides (xylose, mannose and glucose). As xylan is the main hemicellulosic polymer in barley husk, xylose is the major sugar present in the prehydrolysis liquors obtained from this raw material. After neutralization and 
Moldes, A.B. et al. A process for the chemical-biotechnological utilization of barley husks

nutrient supplementation, the hydrolyzates can be used as fermentation media to produce xylitol, a low caloric pentitol with sweetening power which has negative heat of solution, anticariogenic properties and is suitable as sugar substitute for diabetics (Parajó et al. 1997, Cruz et al. 2000a). Using continuous fermentation with cell recycle, the production of xylitol from barley husk hydrolyzates can be carried out with productivities as high as $2.53 \mathrm{~g} / \mathrm{L} \cdot \mathrm{h}$ (Cruz et al. 2000b).

Owing to the selective hemicellulose removal caused by prehydrolysis, the solid residue from this processing step is enriched in both cellulose and lignin. In order to convert it in a suitable substrate for enzymatic hydrolysis, a delignification stage (for example, with $\mathrm{NaOH}$ ) must be performed. As lignin forms a physical barrier hindering the access of enzymes to cellulose, delignification should result in increased accessibility, and so in an improved glucose yield with faster reaction rate. Alkaline treatments achieve other collateral effects (for example, alteration in the physicochemical features of cellulose such as crystallinity and surface area) leading to improved susceptibility toward enzymatic hydrolysis (Gharpuray et al. 1983).

This study deals with the chemical-biotechnological processing of barley husk. In a first step, the hemicellulosic fraction was converted into xylose-containing liquors suitable for xylitol production. The solid phase from prehydrolysis was treated with $\mathrm{NaOH}$ under a variety of operational conditions, and the effects of treatments on both composition and hydrolysis susceptibility of cellulosic substrates were measured.

\section{Material and methods}

\section{Raw material}

Barley husk was kindly provided by San Martín (Ourense, Spain), where husks were separated from the grain by pneumatic conveying and cyclone separation. Husks were stored in a dry and dark place at room temperature until utilization.

\section{Analysis of the raw material}

Aliquots from the homogenized lots were subjected to moisture determination and to quantitative hydrolysis in two-stage, acid treatment (the first step with 72 weight percent sulfuric acid at $30^{\circ} \mathrm{C}$ during 1 hour, and the second one after dilution of the media to 4 weight percent sulfuric acid at $121^{\circ} \mathrm{C}$ during 1 hour) (Vázquez et al. 1991). The solid residue after hydrolysis was considered to be Klason lignin. Hydrolyzates were assayed by HPLC using an Interaction ION300 column (mobile phase, $\mathrm{H}_{2} \mathrm{SO}_{4} 0.01 \mathrm{M}$; flow rate, $0.4 \mathrm{~mL} / \mathrm{min}$; IR and UV detection). This method allowed the direct determination of glucose, xylose, arabinose, acetic acid, ethanol, xylitol, furfural and hydroxymethylfurfural (HMF). Representative material balances are presented in Figure 1.

\section{Chemical processing of samples}

Ground samples of barley husks were hydrolyzed under selected conditions $\left(3 \% \mathrm{H}_{2} \mathrm{SO}_{4}, 15 \mathrm{~min}\right.$, $130^{\circ} \mathrm{C}$, liquid:solid ratio of $8: 1 \mathrm{~g} / \mathrm{g}$ ). The solids from treatments were separated by filtration, washed with water, air dried and treated in autoclave with solutions containing $3-10 \% \mathrm{NaOH}$ at $50-130^{\circ} \mathrm{C}$ during $10-60 \mathrm{~min}$. In this step, the liquor/solid ratio was fixed in $10 \mathrm{~g} / \mathrm{g}$. At the end of treatments, the solid residues were separated by filtration, washed with water, air dried and analyzed as described for the raw material.

\section{Enzymatic hydrolysis}

The commercial enzyme concentrates ("Celluclast" and "Novozym", with cellulase and $\beta$-glucosidase acitivities, respectively) used in experiments were kindly provided by Novo, Denmark. 
Vol. 11 (2002): 51-58.

Fig. 1. Scheme proposed for the chemical-biotechnological processing of barley husks.

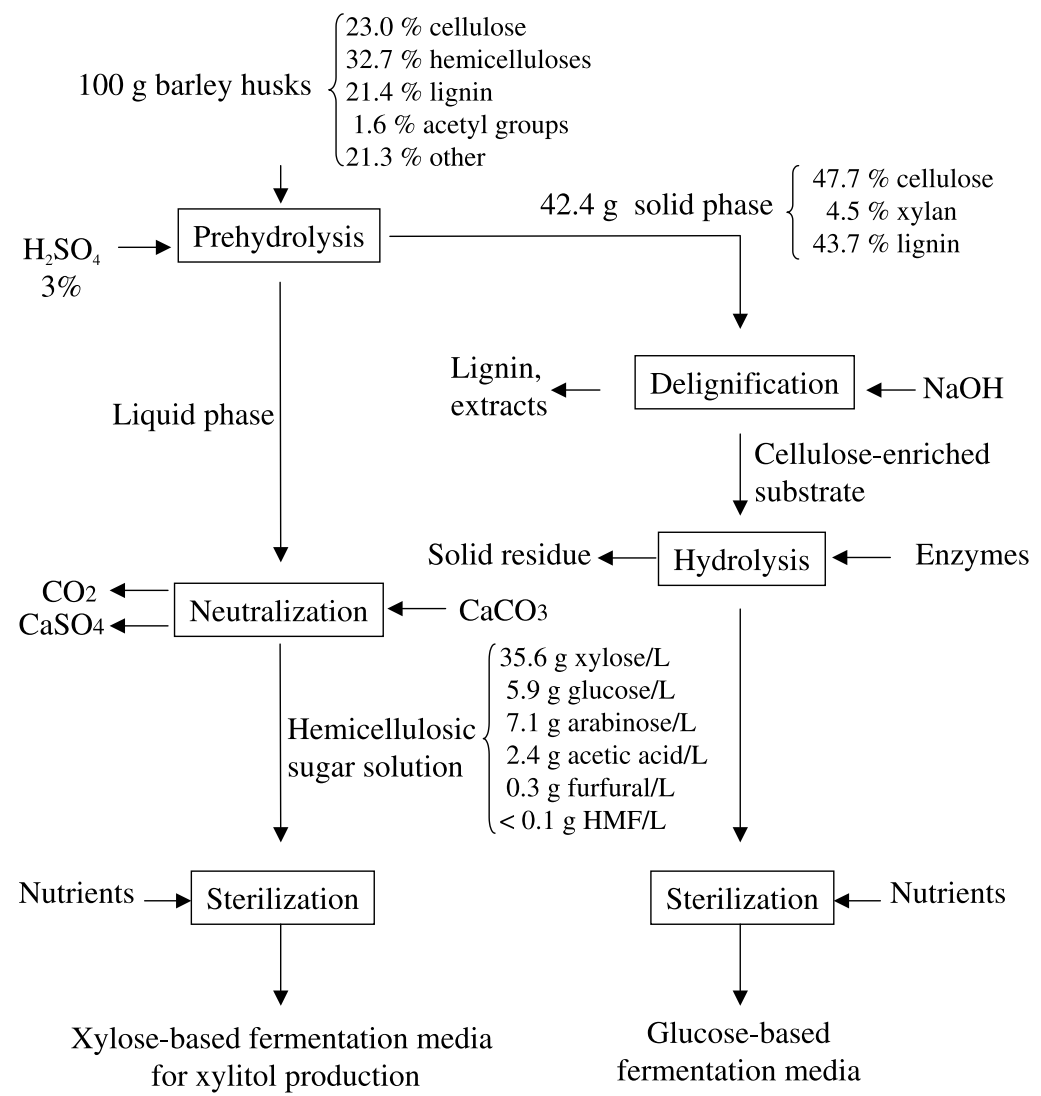

The cellulase activity of concentrates was assayed by the Filter Paper Activity test (FPA) according to Mandels et al. (1976) and expressed as Filter Paper Units (FPU)/mL. The $\beta$-glucosidase activity was measured according to Paquot and Thonart (1982). The operational conditions used in enzymatic hydrolysis were: temperature, $48.5^{\circ} \mathrm{C}$; $\mathrm{pH}, 4.85$; liquor/solid ratio, $30 \mathrm{~g} / \mathrm{g}$; cellulase/substrate ratio, $28 \mathrm{FPU} / \mathrm{g}$ and cellobiase/ cellulase ratio, 13 IU/FPU (Moldes et al. 2000).

\section{Experimental design and statistical analysis}

In the alkaline stage of barley husk processing, an incomplete $3^{3}$ factorial design (Box et al. 1978) was used to study the influence of tem- perature, reaction time and $\mathrm{NaOH}$ concentration on both the composition of the solid substrates from treatments and their susceptibility to enzymatic hydrolysis. The experimental data were analyzed by the Response Surface methodology using the Statistica 5.0 software. The interrelationship between dependent and operational variables was established by a model including linear, interaction and quadratic terms:

$$
\begin{aligned}
\mathrm{Y}= & \mathrm{b}_{0}+\mathrm{b}_{1} \cdot \mathrm{x}_{1}+\mathrm{b}_{2} \cdot \mathrm{x}_{2}+\mathrm{b}_{3} \cdot \mathrm{x}_{3}+\mathrm{b}_{12} \cdot \mathrm{x}_{1} \cdot \mathrm{x}_{2} \\
& +\mathrm{b}_{13} \cdot \mathrm{x}_{1} \cdot \mathrm{x}_{3}+\mathrm{b}_{23} \cdot \mathrm{x}_{2} \cdot \mathrm{x}_{3}+\mathrm{b}_{11} \cdot \mathrm{x}_{1}{ }^{2}+\mathrm{b}_{22} \cdot \mathrm{x}_{2}{ }^{2} \\
& +\mathrm{b}_{33} \cdot \mathrm{x}_{3}{ }^{2}
\end{aligned}
$$

where $\mathrm{Y}$ is the dependent variable, $\mathrm{b}$ denotes the regression coefficients (calculated from experimental data by multiple regression using the least-squares method), and $\mathrm{x}$ denotes the independent variables. 
Moldes, A.B. et al. A process for the chemical-biotechnological utilization of barley husks

\section{Results and discussion}

The sequential treatment of barley husk with sulfuric acid and sodium hydroxide allows the benefit of hemicelluloses and cellulose. Figure 1 shows some details on the composition of liquors and solid residues from treatments. The hydrolyzates coming from the first step have been successfully employed for the production of xylitol, and the corresponding results have been reported in a previous study (Cruz et al. 2000b). Using cell recycle after membrane separation, the fermentation of hydrolyzates with the yeast Debaryomyces hansenii led to a maximum volumetric productivity of $2.53 \mathrm{~g} / \mathrm{L} \cdot \mathrm{h}$ at a dilution rate of $0.284 \mathrm{~h}^{-1}$.

In order to assess the possibility of reaching a simultaneous benefit of both liquid and solid phases coming from the prehydrolysis step, preliminary enzymatic hydrolysis assays were carried out using the solid residues from prehydrolysis as substrates. As expected, these substrates showed a poor susceptibility toward enzymatic hydrolysis (data not shown) owing to their high lignin content. In order to improve the results, a delignification stage with $\mathrm{NaOH}$ was carried out before the enzymatic hydrolysis.
The independent variables used in this study and their variation ranges were: temperature $\mathrm{T}$, $50-130^{\circ} \mathrm{C}$; duration of treatments $t, 10-60 \mathrm{~min}$ and $\mathrm{NaOH}$ concentration $[\mathrm{NaOH}], 3-10$ weight percent of solution. The standardized (coded) adimensional variables employed, having variations limits $(-1,1)$, were defined as $\mathrm{x}_{1}$ (coded temperature), $\mathrm{x}_{2}$ (coded time) and $\mathrm{x}_{3}$ (coded $\mathrm{NaOH}$ concentration). The correspondence between coded and uncoded variables was established by linear equations deduced from their respective variation limits (see Table 1).

Table 1 also lists the dependent variables considered: the composition of delignified solids was measured by variables $\mathrm{y}_{1}$ (cellulose content of samples, g/100 g oven-dry substrate), $y_{2}$ (hemicellulose content of samples, g/100 g ovendry substrate) and $y_{3}$ (Klason lignin content of samples, g/100 g oven-dry substrate); whereas $\mathrm{y}_{4}$ (defined as conversion of cellulose into glucose) was selected to measure the susceptibility of prehydrolyzed, alkali-treated samples toward enzymatic hydrolysis. It can be noted that the processed samples also contained other fractions different from those measured by $\mathrm{y}_{1}, \mathrm{y}_{2}$ and $\mathrm{y}_{3}$ (such as acid-soluble lignin, acetyl groups, ashes, etc.) which were of minor importance for this study.

Table 1. Variables used in this study.

\begin{tabular}{|c|c|c|c|}
\hline Variable & Nomenclature & Units & Variation range \\
\hline \multicolumn{4}{|l|}{ Independent variables } \\
\hline Temperature & $\mathrm{T}$ & ${ }^{\circ} \mathrm{C}$ & $50-130$ \\
\hline Time & $\mathrm{t}$ & Min & $10-60$ \\
\hline $\mathrm{NaOH}$ concentration & {$[\mathrm{NaOH}]$} & wt $\%$ & $3-10$ \\
\hline \multicolumn{4}{|l|}{ Dimensionless, coded independent variables } \\
\hline Dimensionless temperature & $\mathrm{x}_{1}$ & $(\mathrm{~T}-90) / 40$ & $(-1,1)$ \\
\hline Dimensionless time & $\mathrm{x}_{2}$ & $(\mathrm{t}-35) / 25$ & $(-1,1)$ \\
\hline Dimensionless $\mathrm{NaOH}$ concentration & $\mathrm{x}_{3}$ & $([\mathrm{NaOH}]-6.5) / 3.5$ & $(-1,1)$ \\
\hline \multicolumn{4}{|l|}{ Dependent variables } \\
\hline Cellulose content, g /100 g o. d. sample & $\mathrm{y}_{1}$ & & \\
\hline Hemicellulose content, g /100 g o. d. sample & $\mathrm{y}_{2}$ & & \\
\hline Lignin content, g /100 g o. d. sample & $\mathrm{y}_{3}$ & & \\
\hline Cellulose conversion into glucose, & & & \\
\hline g glucose/100 g potential glucose & $\mathrm{y}_{4}$ & & \\
\hline
\end{tabular}


Vol. 11 (2002): 51-58.

Table 2. Operational conditions considered in this study (expressed in terms of the coded independent variables dimensionless temperature $\mathrm{x}_{1}$, dimensionless time $\mathrm{x}_{2}$ and dimensionless $\mathrm{NaOH}$ concentration $\mathrm{x}_{3}$ ) and experimental results achieved for the dependent variables $\mathrm{y}_{1}$ (cellulose content of samples, $\%$ ), $\mathrm{y}_{2}$ (hemicellulose content of samples, $\%$ ), $\mathrm{y}_{3}$ (lignin content of samples, \%) and $\mathrm{y}_{4}$ (cellulose conversion into glucose, $\%$ ).

\begin{tabular}{|c|c|c|c|c|c|c|c|}
\hline \multirow[b]{2}{*}{ Exper. } & \multicolumn{3}{|c|}{ Operational conditions } & \multicolumn{4}{|c|}{ Experimental results } \\
\hline & $\mathrm{x}_{1}$ & $x_{2}$ & $x_{3}$ & $\mathrm{y}_{1}$ & $\mathrm{y}_{2}$ & $\mathrm{y}_{3}$ & $\mathrm{y}_{4}$ \\
\hline 1 & 0 & -1 & -1 & 68.3 & 5.2 & 24.0 & 89.6 \\
\hline 2 & 0 & 1 & -1 & 64.2 & 3.0 & 27.0 & 99.7 \\
\hline 3 & 0 & -1 & 1 & 71.0 & 2.8 & 22.5 & 91.9 \\
\hline 4 & 0 & 1 & 1 & 79.8 & 2.5 & 16.2 & 91.0 \\
\hline 5 & -1 & -1 & 0 & 68.2 & 4.6 & 24.0 & 79.6 \\
\hline 6 & -1 & 1 & 0 & 69.3 & 4.2 & 23.0 & 86.5 \\
\hline 7 & 1 & -1 & 0 & 80.1 & 3.0 & 15.6 & 96.0 \\
\hline 8 & 1 & 1 & 0 & 86.1 & 4.2 & 6.8 & 91.9 \\
\hline 9 & -1 & 0 & -1 & 64.5 & 6.3 & 26.0 & 77.6 \\
\hline 10 & -1 & 0 & 1 & 70.2 & 3.4 & 23.5 & 86.8 \\
\hline 11 & 1 & 0 & -1 & 75.9 & 3.0 & 18.8 & 93.6 \\
\hline 12 & 1 & 0 & 1 & 84.7 & 3.0 & 11.4 & 94.3 \\
\hline 13 & 0 & 0 & 0 & 75.0 & 3.1 & 19.0 & 99.7 \\
\hline 14 & 0 & 0 & 0 & 75.0 & 3.1 & 17.5 & 98.8 \\
\hline 15 & 0 & 0 & 0 & 74.8 & 2.9 & 18.6 & 100.4 \\
\hline
\end{tabular}

Since a systematic study of the effects caused by the operational variables on composition and hydrolysis susceptibility would require a great amount of experimental work, an incomplete, factorial design of experiments was carried out. Several research groups used phenomenological models based on experimental designs to study the chemical processing and/or bioconversion of lignocellulosic materials (Parajó et al. 1995, Roberto et al. 1995, Alves et al. 1998, Mayerhoff et al. 1998, Silva and Roberto 1999). In this study, we utilized an incomplete factorial design, in which 3 dependent variables were assayed at 3 levels. Based on experimental data, equations including linear, interaction and quadratic terms were employed to describe the interrelationship between operational and experimental variables.

Table 2 shows the set of experimental conditions assayed (expressed in terms of coded variables), as well as the experimental data obtained for variables $\mathrm{y}_{1}$ to $\mathrm{y}_{4}$. The sequence for the experimental work was randomly established to limit the influence of systematic errors on the interpretation of results. It can be noted that ex- periments $13-15$ are replications in the central point of the design measuring the experimental error.

Table 3 lists the regression coefficients and their statistical significance (based on a t-test). The same Table includes statistical parameters $\left(\mathrm{r}^{2}\right.$ and $\left.\mathrm{F}\right)$ measuring the correlation and the statistical significance of the models, respectively. It can be noted that all the models showed good statistical parameters for correlation and significance and allowed a close reproduction of experimental data.

In the range tested, the reaction time caused only minor effects on the cellulose content of samples, as it can be seen from the absolute value of the corresponding coefficients. Figure 2 shows the predicted dependence of the cellulose content of samples $\left(\mathrm{y}_{1}\right)$ on the most influential operational variables ( $\mathrm{T}$ and $[\mathrm{NaOH}]$ ) in experiments lasting $35 \mathrm{~min}$. Increased severity (defined by high values of temperature and/or $\mathrm{NaOH}$ concentration) resulted in remarkable increases in the cellulose content of samples. The effects caused by increased alkali concentrations were 
Moldes, A.B. et al. A process for the chemical-biotechnological utilization of barley husks

Table 3. Regression coefficients, significance level and statistical parameters ( $\mathrm{r}^{2}$ and $\left.\mathrm{F}\right)$ measuring the correlation an significance of the models.

a) Regression coefficients and significance

\begin{tabular}{|c|c|c|c|c|}
\hline Coefficients & $\mathrm{y}_{1}$ & $\mathrm{y}_{2}$ & $\mathrm{y}_{3}$ & $\mathrm{y}_{4}$ \\
\hline $\mathrm{b}_{0}$ & $74.93 *$ & $3.033^{*}$ & $18.37 *$ & $99.63 *$ \\
\hline$b_{1}$ & $6.84^{*}$ & $-0.663^{*}$ & $-5.49 *$ & $5.66^{*}$ \\
\hline $\mathrm{b}_{11}$ & $2.00 *$ & $0.758^{*}$ & $-1.76^{*}$ & $-8.06^{*}$ \\
\hline $\mathrm{b}_{2}$ & $1.46^{*}$ & $-0.213^{*}$ & $-1.64 *$ & $1.50 *$ \\
\hline $\mathrm{b}_{22}$ & $-1.03 *$ & $0.208 * *$ & 0.74 & $-3.08^{*}$ \\
\hline$b_{3}$ & $4.10 *$ & $-0.725^{*}$ & $-2.78 *$ & 0.42 \\
\hline $\mathrm{b}_{33}$ & $-3.11 *$ & 0.133 & $3.32 *$ & $-3.53^{*}$ \\
\hline$b_{12}$ & $1.22 *$ & $0.400 *$ & $-1.95^{*}$ & $-2.76^{*}$ \\
\hline$b_{13}$ & $0.78^{*}$ & $0.725^{*}$ & $-1.23 * *$ & $-2.14 *$ \\
\hline $\mathrm{b}_{23}$ & $3.23 *$ & $0.475^{*}$ & $-2.33^{*}$ & $-2.76^{*}$ \\
\hline
\end{tabular}

* Significant coefficients at the $95 \%$ confidence level

** Significant coefficients at the $90 \%$ confidence level

b) Statistical parameters measuring the correlation and significance of models

\begin{tabular}{lcccc}
\hline Variable & $\mathrm{R}^{2}$ & Corrected $\mathrm{R}^{2}$ & $\mathrm{~F}_{\text {exp }}$ & Significance level (based on the F test) \\
\hline $\mathrm{y}_{1}$ & 0.9942 & 0.9839 & 90.99 & $>99 \%$ \\
$\mathrm{y}_{2}$ & 0.8779 & 0.6582 & 47.81 & $>99 \%$ \\
$\mathrm{y}_{3}$ & 0.9753 & 0.9310 & 5.25 & $>95 \%$ \\
$\mathrm{y}_{4}$ & 0.9414 & 0.8359 & 20.29 & $>99 \%$ \\
\hline
\end{tabular}

more marked when the experiments were carried out at the highest temperature assayed. Under the severest conditions considered $\left(130^{\circ} \mathrm{C}\right.$, $10 \% \mathrm{NaOH})$, the model predicted cellulose con-

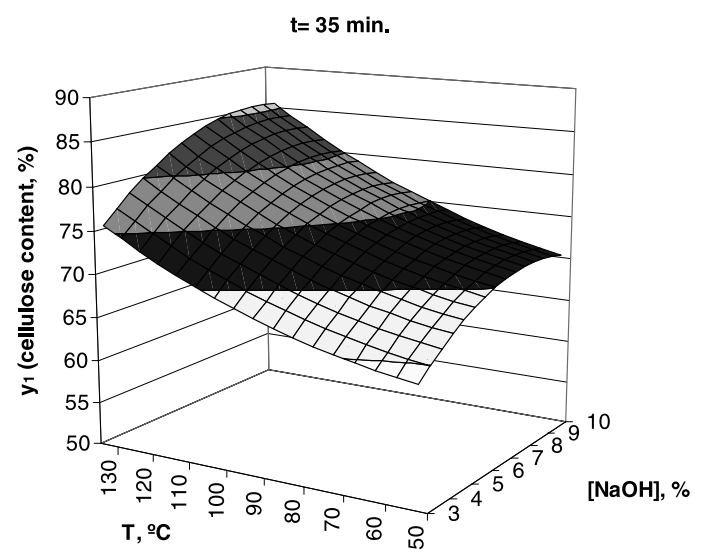

Fig. 2. Dependence of the cellulose content of samples (variable $\mathrm{y}_{1}$ ) on $\mathrm{NaOH}$ concentration and temperature predicted for samples delignified for $35 \mathrm{~min}$. tents as high as $86 \%$, confirming the suitability of the alkaline processing for delignification.

The experimental results achieved for the hemicellulose content of samples (measured by $\mathrm{y}_{2}$ ) varied within a narrow range $(2.9-6.3 \%)$. The surface response shown in Figure 3 (calculated for assays lasting $35 \mathrm{~min}$ ) shows a continuous decrease in $\mathrm{y}_{2}$ with temperature for experiments with $3 \% \mathrm{NaOH}$. However, the model predicted a slight increase in the hemicellulose content of samples with temperature, which can be justified on the basis of both experimental and fitting errors. Operating at $130^{\circ} \mathrm{C}$, the hemicellulose content of samples remained almost constant with the $\mathrm{NaOH}$ concentration, confirming that the hemicellulose solubilization was completed at high temperature even in media containing the lowest $\mathrm{NaOH}$ concentration tested.

Figure 4 shows the predicted dependence of variable $\mathrm{y}_{3}$ (lignin content of samples) on the most influential operational variables ( $\mathrm{T}$ and $[\mathrm{NaOH}])$ for treatments lasting $35 \mathrm{~min}$. As ex- 
Vol. 11 (2002): 51-58.

$\mathrm{t}=\mathbf{3 5} \mathrm{min}$

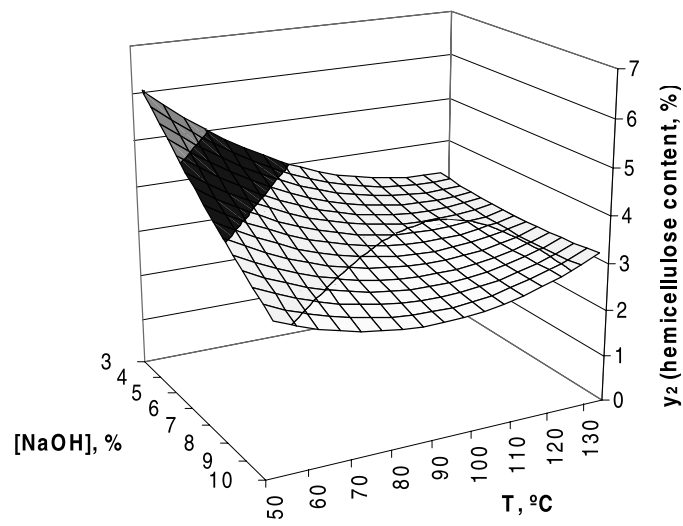

Fig. 3. Dependence of the hemicellulose content of samples (variable $\mathrm{y}_{2}$ ) on $\mathrm{NaOH}$ concentration and temperature predicted for samples delignified for $35 \mathrm{~min}$.

pected, the response surface predicted lower lignin contents for higher temperatures at a given $\mathrm{NaOH}$ concentration. Comparatively, the effects caused by the $\mathrm{NaOH}$ concentration on the lignin content were of minor importance.

The most important variable for the objectives of this work was the cellulose conversion achieved in the enzymatic hydrolysis step $\left(\mathrm{y}_{4}\right)$. The experimental data listed in Table 2 show that all the alkali-treated samples were highly susceptible toward the enzymatic hydrolysis, with 77.6-100\% cellulose conversion into glucose. Cellulose conversions below $86 \%$ were obtained only in experiments 5 and 9, which corresponded to assays performed at the lowest temperature considered $\left(50^{\circ} \mathrm{C}\right)$ with either short treatments $\left(x_{2}=-1\right.$ in experiment 5) or low $\mathrm{NaOH}$ concentrations $\left(x_{3}=-1\right.$ in experiment 9$)$. When low-temperature delignification was combined with either prolonged reaction times (such as in experiment 6) or high $\mathrm{NaOH}$ concentrations (such in experiment 10), the cellulose conversion increased significantly $\left(\mathrm{y}_{4}\right.$ up to 86.5$86.8 \%$ ). Harsher delignification conditions resulted in increased susceptibility toward enzymatic hydrolysis. The experimental results of Table 2 show that enzymatic hydrolysis yields higher than $93 \%$ can be obtained under a variety

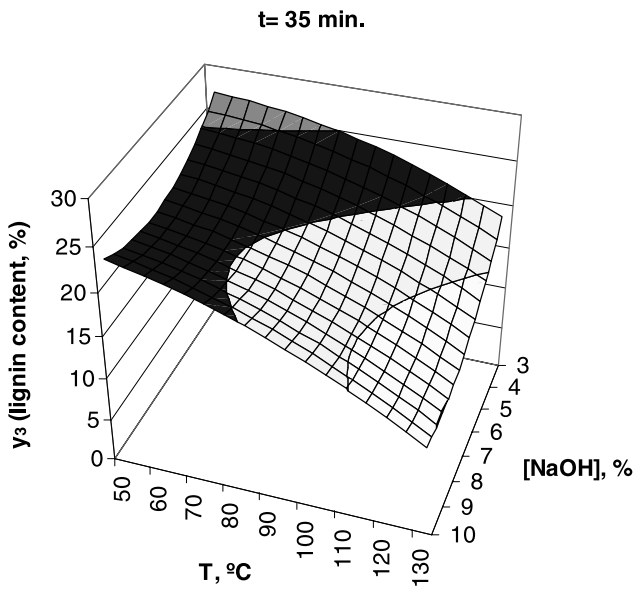

Fig. 4. Dependence of the lignin content of samples (variable $\mathrm{y}_{3}$ ) on $\mathrm{NaOH}$ concentration and temperature predicted for samples delignified for $35 \mathrm{~min}$.

$t=35 \mathrm{~min}$.

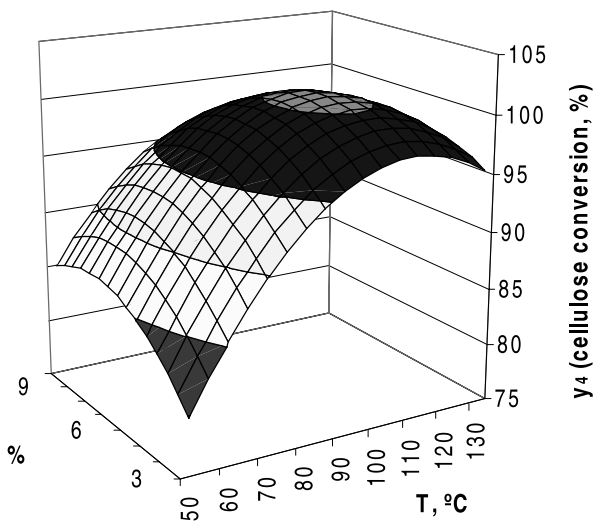

Fig. 5. Dependence of the cellulose conversion into glucose (variable $\mathrm{y}_{4}$ ) on $\mathrm{NaOH}$ concentration and temperature predicted for samples delignified for $35 \mathrm{~min}$.

of operational conditions. Figure 5, which shows the predicted dependence of the cellulose conversion on the operational variables $\mathrm{T}$ and $[\mathrm{NaOH}]$, confirms the above findings: the major effects on $\mathrm{y}_{4}$ are caused by temperature, particularly in the range $50-100^{\circ} \mathrm{C}$. The decreased cellulose conversions predicted at high temperatures and alkali concentrations can be justified on the basis of both experimental and fitting errors. For treatments lasting $35 \mathrm{~min}, 94-100 \%$ 
Moldes, A.B. et al. A process for the chemical-biotechnological utilization of barley husks

cellulose conversion is predicted for samples delignified at temperatures above $80^{\circ} \mathrm{C}$ even in treatments carried out with the minimum $\mathrm{NaOH}$ charge considered.

In conclusion, the sequential treatment of barley husk with sulfuric acid and sodium hydroxide allows a simultaneous benefit of the hemicelluloses and cellulose fractions to produce xylitol and glucose solutions respectively. The prehydrolyzed barley husk, after being subject- ed to an alkaline treatment, shows high cellulose content (up to $86 \%$ ) and shows an excellent susceptibility toward enzymatic hydrolysis, with near quantitative glucose yields.

Acknowledgements. Authors are grateful to "Xunta de Galicia" (Project XUGA 38303A98) and to the University of Vigo (Project 64502 K904) for the financial support of this work, as well as to Ms. Aida Ramos Nespereira and Antonia Rodríguez Jardón for their excellent technical assistance.

\section{References}

Alves, L.A., Felipe, M.G.A., Silva, J.B.A.E., Silva, S.S. \& Prata, A.M.R. 1998. Pretreatment of sugarcane bagasse hemicellulose hydrolysate for xylitol production by Candida guilliermondii. Applied Biochemistry and Biotechnology 70-72: 89-98.

Box, G.E.P., Hunter, W.G. \& Hunter, J.S. 1978. Statistic for experimenters: an introduction to design, data analysis and model building. John Wiley, New York. p. $125-175$.

Cruz, J.M., Domínguez, J.M., Domínguez, H. \& Parajó, J.C. 2000a. Preparation of fermentation media from agricultural wastes and their bioconversion into xylitol. Food Biotechnology 14, 1\&2: 79-97.

Cruz, J.M., Domínguez, J.M., Domínguez, H. \& Parajó, J.C. 2000 b. Xylitol production from barley bran hydrolysates by continuous fermentation with $D e$ baryomyces hansenii. Biotechnology Letters 22: 1895-1898.

Gharpuray, M.M., Fan, L.T. \& Lee, Y.H. 1983. Caustic pretreatment study for enzymatic hydrolysis of wheat straw. Wood and Agricultural Residues 1: 369-389.

Mandels, M., Andreotti, R. \& Roche, C. 1976. Measurement of saccharifying cellulose. Biotechnology Bioengineering Symposium 6: 21-33.

Mayerhoff, Z.D.V.L., Roberto, I.C. \& Silva, S.S. 1998. Production of xylitol by Candida mogii from rice straw hydrolysate. Study of environmental effects using statistical design. Applied Biochemistry and Biotechnology 70-72: 149-159.
Moldes, A.B., Alonso, J.L. \& Parajó, J.C. 2000. Multi-step feeding systems for lactic acid production by simultaneous saccharification and fermentation of processed wood. Bioprocess Engineering 22: 175-180.

Paquot, M. \& Thonart, Ph. 1982. Hydrolyse enzymatique de la cellulose regenerée. Holzforschung 36: 177181.

Parajó, J.C., Alonso, J.L. \& Santos, V. 1995. Enzymatic hydrolysis of wood: an engineering assessment. Bioprocess Engineering 12: 253-261.

Parajó, J.C., Domínguez, H. \& Domínguez, J.M. 1997. Improved xylitol production with Debaryomyces hansenii Y-7426 from raw or detoxified wood hydrolyzates. Enzyme Microbiology Technology 21: 18-24.

Roberto, I.C., Sato, S., Mancilha, I.M. \& Taqueda, M.E.S. 1995. Influence of media composition on xylitol fermentation by Candida guilliermondii using response surface methodology. Biotechnology Letters 17, 11: 1223-1228.

Silva, C.J.S.M. \& Roberto, I.C. 1999. Statistical screening method for selection of important variables on xylitol biosynthesis from rice straw hydrolysate by Candida guilliermondii FTI 20037. Biotechnology Techniques 13: 743-747.

Vázquez, D., Lage, M.A., Parajó, J.C. \& Vázquez, G. 1991. Transformación de materiales lignocelulósicos: Composición, fraccionamiento y aprovechamiento. Revista Agroquimica Tecnología de Alimentos 31, 2: 143-164. 